\title{
Influencing Factor Analysis of Urban Wastewater Emissions
}

\author{
Cheng Wang \\ School of Mathematics and Economics, Hubei University of Education, \\ Wuhan 430205, P. R. China \\ wangc80@163.com
}

Keywords: Urban wastewater emissions; Influencing factor; Grey correlation analysis

Abstract. Water is the source of life, and it is a necessary condition for existence and economic development. In this paper, the problem of analyzing the influencing factors of urban wastewater emissions is studied, and an optimal model of analyzing the influencing factors is presented based on the grey correlation analysis method. Moreover, an application example of analyzing the influencing factors of urban wastewater emissions in Hubei province is given to show the availability and feasibility of the presented model.

\section{Introduction}

Urbanization is the inevitable results under the social and economic development, and is the objective form of social form to high level development. With the speeding up of urbanization, the urban sewage emissions also accelerated sharply. So the urban sewage emissions has become identifying whether a city to reach a high standard of important basis, more and more attention by people, the scientific analysis is the premise to solve the urban sewage recycling. Urban sewage system is a complex system, which is effected by natural conditions, population, policy, standard of living, living habits and other factors. Reasonable analysis and determine the main factors that influence the wastewater discharge right to predict wastewater has a very important role.

Urban sewage system is complex and is affected by many factors. We can analyze the main influencing factors starting from its connotation. Main influence factors can be selected from the comprehensive and quantifiable aspects, then the effective factor is found out and the invalid factor is eliminated. In this paper, we determined the influencing factors that influence the Beijing municipal sewage emissions by using grey relational analysis method.

\section{Influencing Factor of Urban Wastewater Emissions}

The development of the city should be embodied in the comprehensive aspects of economy, society, environment, science and technology, and so on.

City living water and industrial water consumption has a very close relationship with urban sewage emissions. The greater the urban living water and industrial water consumption is, the greater the urban sewage emissions is greater. The main factors that influence the urban domestic water system including urban non-agricultural population, the condition of the third industry, building area, living standards, green space and road, etc., and the green space and road related to the green land area and rainfall. Urban population is the main influence factors of city life sewage, thus we select the non-agricultural population factor to represent the population of Hubei province. The tertiary industry output value and building area is the main influence factors of public water, which accounts for the proportion of domestic water public water is larger, so we select the third industry production value and the factors influencing the construction area as the influence factors. Because the construction area of data is difficult to obtain, so we choose the per capita living space.

Per capita living space not only reflects the improvement of living facilities, but also highlight the improvement of health facilities. Moreover, the increase of per capita living space is also a sign of people's economic level rising, and the third industry water consumption will increase, so the per capita living area will lead to higher per capita water use quota. Therefore, we mainly choose four factors, i.e., 
non-agricultural population, per capita living area, the tertiary industry output value and green space factor (the ratio of the current year green space area and rainfall).

The main factors that influence the industrial water system include industrial structure, water price adjustment and industrial water saving, etc. The adjustment of industrial structure means that the adjustment of the industrial water, thus we select industrial organization as the influence factors of industrial water use.

Price promotion of urban industrial water not only can guarantee the construction and operation of treatment facilities of industrial wastewater, but also can improve the production technology of enterprises with high water consumption, and also can strengthen water saving and sewage recovery. So the water price adjustment is an important factor of industrial water use. With the shortage of water resources, to ensure the good operation of the enterprise, enterprises will phase out water equipment with high consumption to make the enterprise sewage emissions down. Therefore, we select three factors, i.e., water price adjustment, industrial structure, and industrial water saving.

Shortage of water resources is one of the most serious resource problems in the 21 st century, its reason mainly includes the water consumption has increased dramatically, water pollution, unreasonable water resources utilization, and water resources waste.

To sum up, the influence factors (16 factors) of wastewater can be divided into four kinds. Now the 16 factors are regarded as independent variables and the municipal sewage emissions as the dependent variable. The decision task is seeking the main influence factors among 16 factors which influence on municipal sewage emissions.

\section{Influencing Factor of Urban Wastewater Emissions}

In order to determine the correlation between urban wastewater emissions $\left(A_{0}\right)$ and the 16 influencing factors, i.e., per capita disposable income $\left(A_{1}\right)$, per capita public green area $\left(A_{2}\right)$, per capita living area $\left(A_{3}\right)$, the urban population of water penetration $\left(A_{4}\right)$, sewage treatment rate $\left(A_{5}\right)$, the proportion of public education spending in GDP $\left(A_{6}\right)$, non-agricultural population $\left(A_{7}\right)$, the output value of the third industry $\left(A_{8}\right)$, the green space factor $\left(A_{9}\right)$, industrial structure $\left(A_{10}\right)$, water price adjustment $\left(A_{11}\right)$, industrial water saving $\left(A_{12}\right)$, total water consumption $\left(A_{13}\right)$, the consumer price index $\left(A_{14}\right)$, average temperature $\left(A_{15}\right)$, the population of permanent residents $\left(A_{16}\right)$, this paper will establish a grey analysis model. The related data are shown in Table 1-2.

Table 1. The original data for urban wastewater emissions and 16 influence factors

\begin{tabular}{|c|c|c|c|c|c|c|c|c|c|c|}
\hline Factors & 2005 & 2006 & 2007 & 2008 & 2009 & 2010 & 2011 & 2012 & 2013 & 2014 \\
\hline$A_{0}$ & 101009 & 104922 & 107816.7 & 113259 & 140812.9 & 136415 & 145469 & 140273.7 & 144579.9 & 150713.6 \\
\hline$A_{1}$ & 17653 & 19977.5 & 21988.7 & 24724.9 & 26738.5 & 29072.9 & 32903 & 36468.8 & 36469 & 43910 \\
\hline$A_{2}$ & 0.00088 & 0.00092 & 0.00083 & 0.00081 & 0.00114 & 0.00112 & 0.00113 & 0.00118 & 0.00127 & 0.00124 \\
\hline$A_{3}$ & 18.805 & 20.402 & 20.680 & 20.479 & 20.288 & 19.599 & 19.702 & 19.511 & 19.321 & 19.134 \\
\hline$A_{4}$ & 100 & 123.36 & 100 & 100 & 100 & 100 & 100 & 100 & 100 & 100 \\
\hline$A_{5}$ & $89.1 \%$ & $90 \%$ & $92 \%$ & $92 \%$ & $93 \%$ & $95 \%$ & $82 \%$ & $83 \%$ & $96.5 \%$ & $97 \%$ \\
\hline$A_{6}$ & 0.4817 & 0.3131 & 0.3225 & 0.3448 & 0.3565 & 0.3639 & 0.3862 & 0.4280 & 0.4516 & 0.4150 \\
\hline$A_{7}$ & 1286 & 1530 & 1416 & 1504 & 1581 & 1686 & 1740 & 1784 & 1825 & 1858 \\
\hline$A_{8}$ & 4854.3 & 5837.6 & 7236.2 & 8375.8 & 9179.2 & 10600.8 & 12363.2 & 13669.9 & 15348.6 & 16627.0 \\
\hline$A_{9}$ & 0.585 & 0.797 & 0.589 & 0.367 & 0.912 & 0.870 & 0.692 & 0.364 & 0.725 & 1.052 \\
\hline$A_{10}$ & 0.696 & 0.719 & 0.734 & 0.753 & 0.755 & 0.751 & 0.760 & 0.764 & 0.787 & 0.779 \\
\hline$A_{11}$ & 6.0 & 6.78 & 7.20 & 7.64 & 7.85 & 8.03 & 8.23 & 8.50 & 8.67 & 9.2 \\
\hline$A_{12}$ & 0.58 & 0.60 & 0.45 & 0.55 & 0 & 0.14 & 0.05 & 0.12 & 0.13 & 0.03 \\
\hline$A_{13}$ & 34.5 & 34.3 & 34.81 & 35.08 & 35.5 & 35.2 & 35.96 & 35.88 & 36.38 & 37.49 \\
\hline$A_{14}$ & 101.5 & 100.9 & 102.4 & 105.1 & 98.5 & 102.4 & 105.6 & 101.3 & 103.3 & 101.6 \\
\hline$A_{15}$ & 6.3 & 7.9 & 10 & 7.4 & 8.0 & 9.2 & 10.4 & 10.8 & 10.2 & 11 \\
\hline$A_{16}$ & 1538 & 1601 & 1676 & 1771 & 1860 & 1962 & 2019 & 2069 & 2115 & 2152 \\
\hline
\end{tabular}


The steps of influencing factor analysis model based on grey correlation analysis are given as follows.

(1) The urban wastewater emissions $\left(A_{0}\right)$ is taken as reference sequence $x_{0}(k), k=1,2, \mathrm{~L}, 10$, and 16 influencing factors as the compared sequences $x_{i}(k), i=1,2, \mathrm{~L}, 16, k=1,2, \mathrm{~L}, 10$, and make the initial value processing for the data in Table 1 , we obtain the standardized data sequences $y_{i}(k)$, $i=1,2, \mathrm{~L}, 16, k=1,2, \mathrm{~L}, 10$.

Table 2. The standardized data sequences

\begin{tabular}{l|cccccccccc}
\hline Factors & 2005 & 2006 & 2007 & 2008 & 2009 & 2010 & 2011 & 2012 & 2013 & 2014 \\
\hline$A_{0}$ & 1 & 1.038 & 1.067 & 1.121 & 1.394 & 1.350 & 1.440 & 1.388 & 1.431 & 1.492 \\
$A_{1}$ & 1 & 1.131 & 1.246 & 1.400 & 1.515 & 1.646 & 1.864 & 2.065 & 2.065 & 2.487 \\
$A_{2}$ & 1 & 1.045 & 0.943 & 0.920 & 1.295 & 1.272 & 1.284 & 1.340 & 1.443 & 1.409 \\
$A_{3}$ & 1 & 1.084 & 1.099 & 1.089 & 1.078 & 1.042 & 1.048 & 1.037 & 1.027 & 1.017 \\
$A_{4}$ & 1 & 1.234 & 1 & 1 & 1 & 1 & 1 & 1 & 1 & 1 \\
$A_{5}$ & 1 & 1.010 & 1.033 & 1.033 & 1.044 & 1.066 & 0.920 & 0.932 & 1.083 & 1.088 \\
$A_{6}$ & 1 & 0.649 & 0.669 & 0.715 & 0.740 & 0.755 & 0.801 & 0.888 & 0.937 & 0.862 \\
$A_{7}$ & 1 & 1.189 & 1.101 & 1.169 & 1.229 & 1.311 & 1.353 & 1.387 & 1.419 & 1.445 \\
$A_{8}$ & 1 & 1.202 & 1.491 & 1.725 & 1.890 & 2.183 & 2.546 & 2.816 & 3.162 & 3.425 \\
$A_{9}$ & 1 & 1.362 & 1.006 & 0.627 & 1.558 & 1.487 & 1.183 & 0.622 & 1.239 & 1.798 \\
$A_{10}$ & 1 & 1.033 & 1.054 & 1.082 & 1.084 & 1.079 & 1.092 & 1.098 & 1.131 & 1.119 \\
$A_{11}$ & 1 & 1.130 & 1.20 & 1.273 & 1.308 & 1.338 & 1.372 & 1.416 & 1.445 & 1.533 \\
$A_{12}$ & 1 & 1.034 & 0.775 & 0.948 & 0 & 0.241 & 0.086 & 0.206 & 0.224 & 0.051 \\
$A_{13}$ & 1 & 0.994 & 1.009 & 1.016 & 1.029 & 1.020 & 1.042 & 1.040 & 1.054 & 1.086 \\
$A_{14}$ & 1 & 0.994 & 1.008 & 1.035 & 0.971 & 1.008 & 1.041 & 0.998 & 1.017 & 1.009 \\
$A_{15}$ & 1 & 1.040 & 1.089 & 1.151 & 1.209 & 1.275 & 1.313 & 1.332 & 1.375 & 1.39 \\
$A_{16}$ & 1 & 1.253 & 1.587 & 1.174 & 1.269 & 1.460 & 1.650 & 1.714 & 1.619 & 1.399 \\
\hline
\end{tabular}

(2) Calculate the absolute difference sequence,

$\Delta_{i 0}(k)=\left|y_{0}(k)-y_{i}(k)\right|$.

(3) Calculate grey correlation coefficient

$$
r\left(x_{0}(k), x_{i}(k)=\frac{\Delta_{\min }+\rho \Delta_{\min }}{\Delta_{i 0}(k)+\rho \Delta_{\min }},\right.
$$

where $\rho=0.5$.

(4) Calculate grey relational degree $r\left(x_{0}, x_{i}\right)=\sum_{k=1}^{n} \omega_{k} r\left(x_{0}(k), x_{i}(k)\right)$, the results are as follows.

$$
\begin{aligned}
& r\left(x_{0}, x_{1}\right)=0.85, r\left(x_{0}, x_{2}\right)=0.67, r\left(x_{0}, x_{3}\right)=0.54, r\left(x_{0}, x_{4}\right)=0.57, \\
& r\left(x_{0}, x_{5}\right)=0.52, r\left(x_{0}, x_{6}\right)=0.49, r\left(x_{0}, x_{7}\right)=0.892, r\left(x_{0}, x_{8}\right)=0.89, \\
& r\left(x_{0}, x_{9}\right)=0.79, r\left(x_{0}, x_{10}\right)=0.56, r\left(x_{0}, x_{11}\right)=0.96, r\left(x_{0}, x_{12}\right)=0.52, \\
& r\left(x_{0}, x_{13}\right)=0.50, r\left(x_{0}, x_{14}\right)=0.51, r\left(x_{0}, x_{15}\right)=0.524, r\left(x_{0}, x_{16}\right)=0.852 .
\end{aligned}
$$

For the more convenient, the sixteen factors can be divided into direct factors (the front 5 factors) and indirect factors (the latter 11 factors). From above values of grey correlation degree, the ranking order for 5 direct factors are as follows.

$$
x_{11} \mathrm{f} x_{7} \mathrm{f} x_{8} \mathrm{f} x_{16} \mathrm{f} x_{1}
$$

which shows that the industrial structure $\left(A_{10}\right)$ is the most main influencing factor. Moreover, for the 11 indirect factors, the ranking order are as follows.

$$
x_{9} \mathrm{f} x_{2} \mathrm{f} x_{10} \mathrm{f} x_{4} \mathrm{f} x_{3} \mathrm{f} x_{5} \mathrm{f} x_{15} \mathrm{f} x_{12} \mathrm{f} x_{14} \mathrm{f} x_{6} \geq x_{13}
$$

which shows that the green space factor $\left(A_{9}\right)$ is the most main indirect influencing factor. 


\section{Conclusions}

This paper studies the problem of analyzing the influencing factors of urban wastewater emissions, and presents an optimal model of analyzing the influencing factor based on the grey correlation analysis method. Specially, an application example of analyzing the influencing factor of urban wastewater emissions in Hubei province is given, the decision results show that industrial structure, sewage treatment rate, penetration rate of urban water, average temperature, are average per capita disposable income are five direct factors which impact on the wastewater emissions, and in the indirect factors, the third industry production value is the most far-reaching influencing factor.

\section{Acknowledgements}

This work is supported by the Natural Science Foundation of Hubei Province (No. 2015CFB420), and the National Natural Science Foundation of China (No. 61403153).

\section{References}

[1] J.L. Deng: The Foundation of Grey Theory (Huazhong University of Science and Technology Press, Wuhan 2002).

[2] X.P. Xiao, Z.M. Song and F. Li: The Foundation and Application of Grey Technology (Science Press, Beijing 2005).

[3] J.J. Sabia and D.M. Anderson: Journal of Health Economics Vol. 20 (2015), p. 14-16.

[4] P. Maria, A.E. Margaretha and P. Jari: Science of the Total Environment Vol. 366 (2005), p. 34-43.

[5] E.Z. Harrison, S.R. Oakes and M. Hysell: Science of the Total Environment Vol. 367 (2006), p. 69-77. 